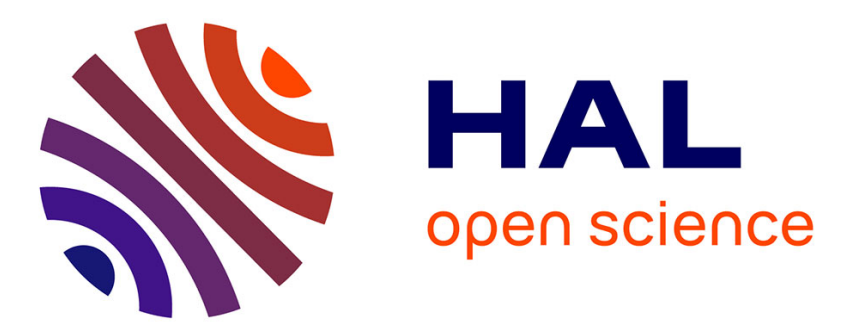

\title{
Real-time dynamic information to road-users: New challenges for urban road network management strategies
}

\author{
Luc Charansonney, Vincent Aguiléra
}

\section{- To cite this version:}

Luc Charansonney, Vincent Aguiléra. Real-time dynamic information to road-users: New challenges for urban road network management strategies. ICNAAM-2014, Sep 2014, Rhodes, Greece. pp.1-5, 10.1063/1.4912738 . hal-01216053

\section{HAL Id: hal-01216053 \\ https://hal-enpc.archives-ouvertes.fr/hal-01216053}

Submitted on 15 Oct 2015

HAL is a multi-disciplinary open access archive for the deposit and dissemination of scientific research documents, whether they are published or not. The documents may come from teaching and research institutions in France or abroad, or from public or private research centers.
L'archive ouverte pluridisciplinaire HAL, est destinée au dépôt et à la diffusion de documents scientifiques de niveau recherche, publiés ou non, émanant des établissements d'enseignement et de recherche français ou étrangers, des laboratoires publics ou privés. 


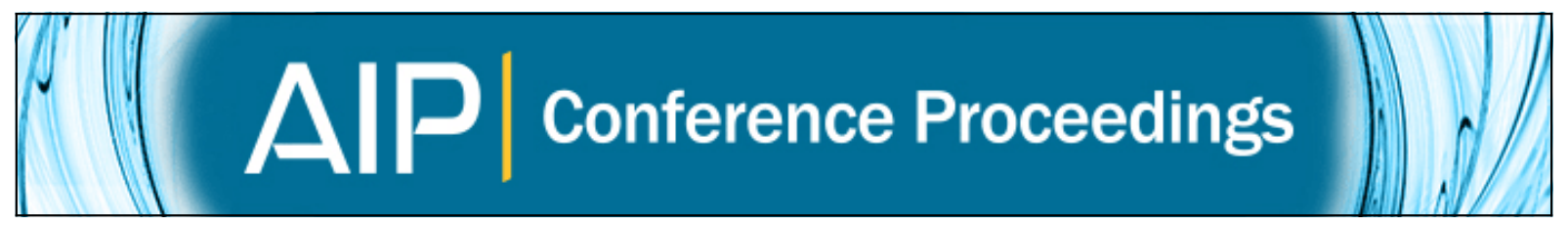

Real-time dynamic information to road-users: New challenges for urban road network management strategies

Luc Charansonney and Vincent Aguiléra

Citation: AIP Conference Proceedings 1648, 530005 (2015); doi: 10.1063/1.4912738

View online: http://dx.doi.org/10.1063/1.4912738

View Table of Contents: http://scitation.aip.org/content/aip/proceeding/aipcp/1648?ver=pdfcov

Published by the AIP Publishing

\section{Articles you may be interested in}

Innovative tools for urban soundscape quality: Real-time road traffic auralization and low height noise barriers J. Acoust. Soc. Am. 137, 2256 (2015); 10.1121/1.4920232

Real-time control of urban drainage system: Optimization of spillways

AIP Conf. Proc. 1648, 190008 (2015); 10.1063/1.4912477

Improving User Management in Networked Systems

AIP Conf. Proc. 1060, 257 (2008); 10.1063/1.3037066

A new integrating real-time analyzer

J. Acoust. Soc. Am. 64, S173 (1978); 10.1121/1.2004021

New Real-Time Spectrum Analyzer

J. Acoust. Soc. Am. 48, 117 (1970); 10.1121/1.1974934 


\title{
Real-time Dynamic Information to Road-users: New Challenges for Urban Road Network Management Strategies
}

\author{
Luc Charansonney* and Vincent Aguiléra ${ }^{\dagger}$ \\ *PCE Lutèce, Direction de la Voirie et des Déplacements, Ville de Paris \\ ${ }^{\dagger}$ Laboratoire Ville Mobilité Transports, Université Paris-Est
}

\begin{abstract}
Urban road authorities mainly rely on traffic demand management strategies to operate the road networks they are in charge of. They used to be the only ones able to gather traffic data, and thus to have an extensive knowledge of their network.

Today's widespread use of GPS and other mobile devices (held by drivers and/or embedded into the vehicles) means that new actors are now able to build a knowledge of the network, and therefore held the necessary material to make decisions as to which routes their users should use. Hence, traffic management is becoming an intricate and complex system where public authorities, private companies and user communities are intertwined, with different aims. The paper thus addresses the following: do centralized traffic information systems still have a meaning nowadays, or in the forthcoming years?

To begin with, the paper provides a comparative analysis of centralized traffic management policies in the cities of London and Paris. This is followed by a short review of new players in the traffic information and data collection market. Finally, a traffic dynamic macroscopic model is proposed in order to study how different classes of users interact on current road networks, each class being characterized by the type and level of information it has access to.
\end{abstract}

Keywords: Dynamic traffic information, Traffic Management

\section{INTRODUCTION}

Urban road authorities mainly rely on traffic demand management strategies to operate the road networks they are in charge of. During daily operations, a complex information system provides guidance and information to road users, using data from traffic loops and other devices. To this end, public authorities have implemented large-scale proprietary traffic management systems. They used to be the one and only actor to have an acute knowledge of their network, and they used to manage the entire information system between the network and the drivers, from traffic loops to information broadcasting through variable-message signs (VMS), FM radio stations or web-based solutions. Over the last decade, new actors have stepped in the road information system. Social media, GPS companies, telecommunication operators are gathering huge amounts of data allowing them, as more cars are equipped with on-board devices and their drivers with smartphones, to have a thorough knowledge of the urban road network state - even on roads with no fixed sensors. Therefore, they can deliver acute real-time information and routing strategies to their customers. Subsequently, there may be an impedance mismatch between the centralized routing strategies elaborated by the road operator and those built from crowdsourced information providers.

Hence, traffic management is becoming an intricate and complex system where public authorities, private companies and user communities are intertwined, with different aims. In this context, this paper addresses one of the arising issues: do centralized traffic information systems still have a meaning ?

The paper is organized as follows. Section "Traffic information: London and Paris" provides a comparative analysis of centralised traffic management policies in the cities of London and Paris. Section "Traffic data collection and trafic information provision" is a short review of new players in the traffic information and data collection market. Section "A model for traffic information" proposes a model to study how different classes of users interact in today's road network, each class being characterized by the type and level of information it has access to.

\section{TRAFFIC INFORMATION: LONDON AND PARIS}

By the late 1990s, the European Union began to consider Intelligent Transport Systems (ITS), among which traveler information and demand management systems, as efficient means to carry out sustainable development policies it 
supported for transport [1]. The full paper will describe in detail the history, evolution, and whereabouts of two metropolitan systems, in London and Paris.

London. This paragraph in the full paper describes the shift in UK transport policy, from the 1980s onwards, from a predict and provide approach - whose main assumption is that growing traffic demand is inevitable, and that therefore capacity increase is the main and most serious answer to congestion problems - to a demand management strategy. This vision was consecrated by the 1991 "Transport: The New Realism" report [2] and its implementation. This paragraph gives an overview of the several authorities that are in charge of the Greater London road network, and the way traffic information is managed and then broadcasted to drivers [3, 4].

Paris. As for London, this paragraph in the full paper describes how the Greater Paris area also suffers from an important fragmentation of authorities, and the systems that are currently in place for the management of demand and broadcasting of traffic information [5, 6, 7]. The full paper develops the different tools that are currently in place for the construction and broadcasting of traffic information in the Paris region.

\section{TRAFFIC DATA COLLECTION AND TRAFIC INFORMATION PROVISION}

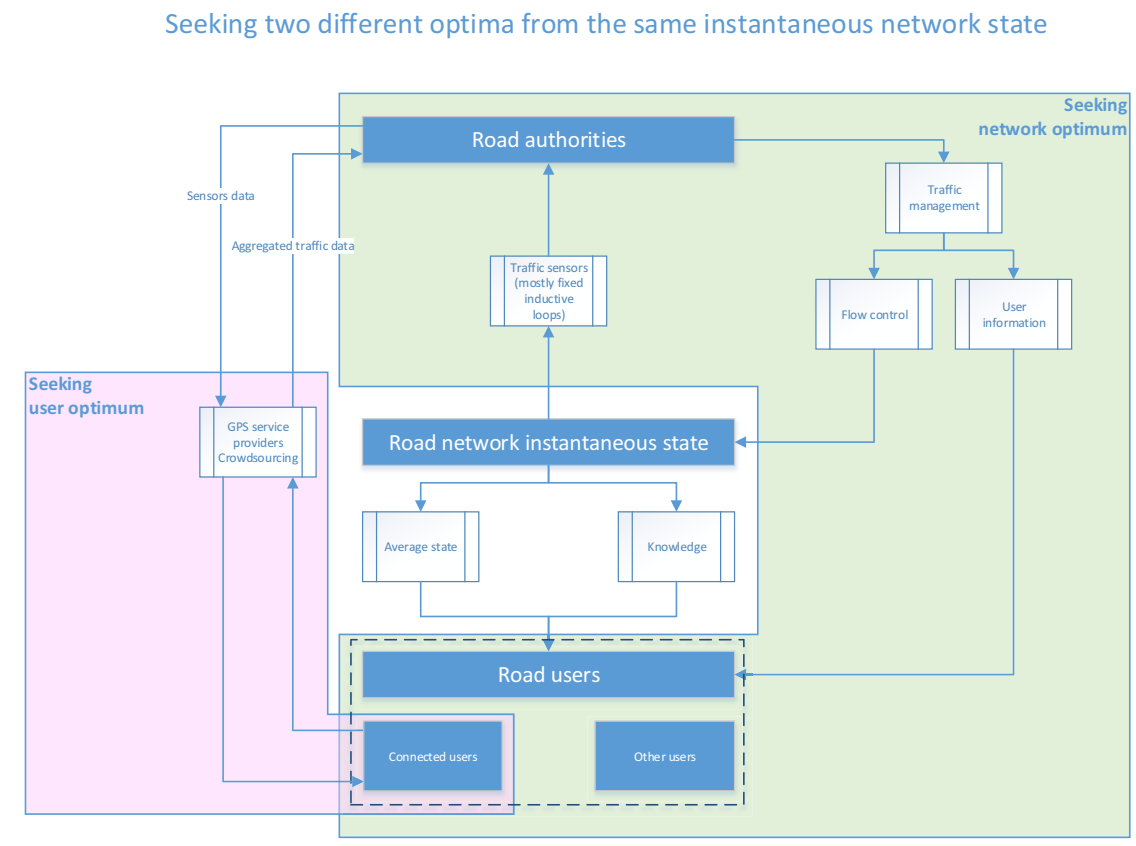

FIGURE 1. Seeking two different optima from the same instantaneous network state.

While road authorities are still using traffic sensors as their primary source of traffic data, the development and democratization of mobile electronic devices for the past twenty years have somehow made drivers and cars new sources of traffic data. Their now exists bluetooth-based road side traffic sensors. Floating Car Data (FCD) and Floating Mobile Data (FMD) are being more and more used. Historically, GPS manufacturers are the first alternate actors facing the public authorities, as GPS-like devices have been globally widespread since about a decade. They provide real time and predictive traffic information, based on their growing fleet of equipped vehicles. Nevertheless, they seem to have taken conscience of the massive role they can play on network management and user information only fairly recently. FMD-based solutions from telecom operators have emerged soon after FCD-based ones.

Social media are the latest newcomers on the traffic information arena. Live traffic information can be found on general purpose social networks and microblogging sites. In fact social media use for incident warning has already 
been described [8, 9]. Text mining techniques are now being developed and experimented [10, 11, 12], like using Twitter messages to describe transport conditions to and from a specific location for a special event. In a way, traffic information on social media both include giving directions - which will then greatly influence how the users choose their routes, especially for, say, often reached destinations — and reporting incidents [11]. Last, but not least, Waze [13] is a dedicated purpose social network that freely provides live traffic information and dynamic guidance to its large and growing user community.

\section{A MODEL FOR TRAFFIC INFORMATION}

Road operators put a lot of efforts in providing information to their users, in order to improve the traffic conditions of the network they are in charge of. The most basic kind of information is provided through static signalling. Drivers are guided along itineraries by the mean of fixed directional signs. Static directional signaling does not allow for managing congestion or exceptional circumstances. Dynamic information, hence dynamic traffic management, appeared with onboard radios, traffic sensors and Variable Message Signs (VMS). Until recently, traffic management has remained a road operator prerogative. Things are changing with crowdsourced traffic information. Users following either their own experience or road operators advices are now mixed with crowdsourced informed users, the latter being likely to follow fastest routes computed on the basis of selfish criteria. This complex set of interactions is illustrated by the block diagram (fig.1). On the one hand, we assume that the authority in charge of an urban road network is targeting a system optimum essentially defined by Wardrop's second principle. To reach this optimum several traffic sensors and traffic controllers are available. Traffic data is processed to define management strategies towards system optimum. If drivers were all to follow this guidance information, the optimum could eventually be reached. On the other hand, if all drivers were to follow selfish real-time guidance information, the dynamic state of the network would likely be close to the so-called Boston Equilibrium [14], where drivers adapt their route choice based on real-time information.

To mathematically present the problem we are addressing, let us consider at first a simple model — initially proposed in [15] and sketched hereafter (sec. "A Simple Model, using Static Assignment") — which can easily be solved by simulation, or even analytically under some assumptions. Next, our model is presented (sec. "Our Model, based on Dynamic Assignment"). While the simple model uses static assignment settings, ours is based on dynamic assignment.

\section{A Simple Model, using Static Assignment}

Let us consider a network made of two links $a$ and $b$, between a single origin $o$ and a single destination $d$. Every day, denoted $k$, there is a flow of $x$ vehicles from $o$ to $d$. The demand $x$ is divided into two parts: a flow of non-equipped users, $y$; and a flow of equipped users, $z$. Here equipped means that users in $z$ have at their disposal an on-board device that allows them to know in advance, every day, which route, either $a$ or $b$, is the fastest to reach $d$ coming from $o$. If, a particular day $k$, the travel time $t_{a, k}$ on $a$ is less than $t_{b, k}$, the flow $z$ follows route $a$. Otherwise, it follows route $b$. non-equipped users in $y$ make their route choice according to their experience on the long term. They are supposed to know the average travel time on $a$ (resp. $b$ ), denoted $\bar{t}_{a}$ (resp. $\bar{t}_{b}$ ). As classically done in static traffic assignment, let us assume that travel times depend on flow by the mean of travel time functions, that is:

$$
t_{r, k}=f_{r}\left(x_{r, k}\right), r \in\{a, b\}
$$

For each day $k$, we have:

$$
\begin{cases}y=y_{a, k}+y_{b, k} & : \text { flow of non-equipped users } \\ z=z_{a, k}+z_{b, k} & : \text { flow of equipped users }\end{cases}
$$

and

$$
\left\{\begin{array}{cl}
x_{a, k}=y_{a, k}+z_{a, k} & : \text { flow on link } a \\
x_{b, k}=y_{b, k}+z_{b, k} & : \text { flow on link } b
\end{array}\right.
$$

The distribution of non-equipped users does not depend on the particular conditions observed a particular day, that is $y_{r, k}=\bar{y}_{r, k}=y_{r}, r \in\{a, b\}$, yielding:

$$
\begin{cases}\overline{x_{a}}=y_{a}+\overline{z_{a}} & : \text { average flow on } \operatorname{arc} a \\ \overline{x_{b}}=y_{b}+\overline{z_{b}} & : \text { average flow on } \operatorname{arc} b\end{cases}
$$


Let us now assume that $\bar{t}_{a}=\bar{t}_{b}$, and that day-to-day variations in travel times are modeled by 0-mean random variables $\delta_{a}$ and $\delta_{b}$, that is:

$$
t_{r, k}=\bar{t}_{r}+\delta_{r, k}, r \in\{a, b\}
$$

Under those assumptions, the distribution of equipped users depends on the probability $p=\operatorname{Pr}\left(\delta_{a}<\delta_{b}\right)$, so that one gets:

$$
\left\{\begin{array}{l}
\overline{z_{a}}=p \times z \\
\overline{z_{b}}=(1-p) \times z
\end{array}\right.
$$

Equations (1) and (2) are interdependent. As exposed in [15], solutions can be found either analytically using reasonable assumptions on the distributions of travel time perturbations $\delta_{a}$ and $\delta_{b}-$ so that $\bar{x}_{r}$ can be expressed from the travel time functions $f_{r}$ and the distribution of $t_{r, k}-$ or numerically using a simulation-based bilevel relaxation algorithm.

\section{Our Model, based on Dynamic Assignment}

Not only to deal with more complex networks than the one used in the previous section, but also to take into account the time dependent variations of traffic flow and traffic management, we have used the macroscopic dynamic traffic assignment model LADTA [16]. Our model is presented with more details in the full paper, together with preliminary results on simple networks. The main ideas are sketched hereafter.

The population of drivers is divided into three categories. Each category is characterized by the level of information it uses to make its route choice, as follows:

Operator Guided Drivers are supposed to follow road guidance information provided by road authorities. At every junction, their route choice stricly follows the posted directional signs, whether static or dynamic.

Experience Guided Drivers are supposed to have a long-term experience of the road network, and they make their route choice based on that. Depending on their departure time, they choose in advance the best route to destination, whatever the particular traffic conditions or directional signaling at this time. Their behavior is very similar to that of $y$-users in the previous section.

Realtime Guided Drivers use real-time information to choose and dynamically adapt their route to destination.

The implemention of those route choice behaviors in LADTA allowed us to study how traffic patterns evolve when the proportions of users in the three categories vary. Detailed results from the following case study are presented in the full paper. The road network is a very simplified version of Paris road network. The demand is expressed as a dynamic OD trip-table. The supply is subject to random disturbances: arc capacities vary during the day to reflect changes in network operations (road works, accidents, road closures, etc).

The algorithm used is based on bilevel relaxation: assuming a given route choice for Experience Guided Drivers allows for running a set of Monte-Carlo simulations with pseudo-randomly generated disturbances. The resulting distributions of Operator Guided Drivers and Realtime Guided Drivers allow the compution of average travel times, as functions of departure time. In turn, those average travel time functions allow the computation of Experience Guided Drivers' route choice. The computation ends once a fixed point is reached.

\section{REFERENCES}

1. E. Commission, A Sustainable Europe for a Better World: A European Union Strategy for Sustainable Development., Tech. rep., European Commission, Brussels (2001).

2. P. Goodwin, S. Hallett, F. Kenny, and G. Stokes, Transport: The New Realism (1992).

3. T. for London, Red routes (2014), URL http://www.tfl.gov.uk/roadusers/redroutes/10185. aspx.

4. U. K. H. Agency, Traffic England: (2014), URL http: / /www.trafficengland.com/.

5. L. Guérin, Transport environnement circulation 176 (2003).

6. D. des routes D'Ile-de France, Sytadin. L'état du trafic en Ile-de-France en temps réel. (2014), URL http: //www. sytadin.fr/.

7. B. James, C. Lancelin, and Y. Durand-Raucher, Transport environnement circulation 126, 14 - 18 (1994), ISSN $0397-6513$.

8. T. Sakaki, M. Okazaki, and Y. Matsuo, "Earthquake shakes Twitter users: Real-time event detection by social sensors," in Proceedings of the 19th International Conference on World Wide Web, WWW'10, Raleigh, NC, 2010, pp. 851-860, ISBN 9781605587998 (ISBN). 
9. T. Sakaki, M. Okazaki, and Y. Matsuo, IEEE Transactions on Knowledge and Data Engineering 25, $919-931$ (2013).

10. S. Carvalho, L. Sarmento, and R. J. F. Rossetti, "Real-time sensing of traffic information in Twitter messages," in 4th Workshop on Artificial Transport Systems and Simulation at IEEE ITSC 2010, Madeira, Portugal, 2010, pp. 19-22.

11. A. Gal-Tzur, S. M. Grant-Muller, T. Kuflik, E. Minkov, S. Nocera, and I. Shoor, Transport Policy 32, 115-123 (2014).

12. A. Gal-Tzur, S. M. Grant-Muller, E. Minkov, and S. Nocera, Procedia-Social and Behavioral Sciences 111, 937-946 (2014).

13. W. Ltd., Waze. Get the best route, every day, with real-time help from other drivers. (2014), URL http: / / www . wa ze. com.

14. T. L. Friesz, D. Bernstein, T. E. Smith, R. L. Tobin, and B. W. Wie, Operations Research 41, 179-191 (1993), ISSN 0030364X.

15. F. Leurent, and T. P. Nguyen, "Network optimization with dynamic traffic information and tolling: a probabilistic model and economic analysis," in 12th World Conference on Transport Research, Lisbon, 2010, ISBN 978-989-96986-1-1.

16. V. Aguiléra, and F. Leurent, "On large size problems of dynamic network assignment and traffic equilibrium: Computational principles and application to Paris road network," in 88th Transportation Research Board Meeting, TRB, Washington (USA), 2009. 